\title{
Welding of titanium alloys
}

\author{
Tim Pasang ${ }^{1, *}$, Yuan Tao ${ }^{1}$, Mana Azizi ${ }^{1}$, Osamu Kamiya $^{2}$, Masami Mizutani ${ }^{3}$, and Wojciech Misiolek ${ }^{4}$ \\ ${ }^{1}$ Department of Mechanical Engineering, Auckland University of Technology, Auckland, New Zealand \\ ${ }^{2}$ Department of System Design Engineering, Faculty of Engineering Science, Akita University, Japan \\ ${ }^{3}$ Joining \& Welding Research Institute, Osaka University, Osaka, Japan \\ ${ }^{4}$ Institute for Metal Forming, Department of Materials Science and Engineering, Lehigh University, Bethlehem, PA18015, USA
}

\begin{abstract}
This article briefly summarises previous reports as well as some recent results on welding of various titanium alloys. Titanium is available in a wide range, hence, their properties and characteristics (including welding characteristics) may also varied significantly. The alloys studied represented three major areas; they are (1): unalloyed or commercially pure titanium (CP Ti), (2): near $\alpha$ and $\alpha+\beta$ alloys, and (3): $\beta$ alloys. From our preliminary results, it can be reported that the structure of fusion zone (FZ) and heat affected zone (HAZ) of alloys from area (1) may change but their hardness remained, arguably, the same as the as-received material. Alloys from area (2) showed an increase in hardness in the FZ and HAZ areas due to the formation of $\alpha$-prime or martensite, while alloys from area (3) experienced a reduction in hardness associated with dissolution of $\alpha$ phase leaving only retained $\beta$ in the FZ. Further investigations are required to confirm these findings. Such information are very useful so that appropriate post welding heat treatment (PWHT) can be applied to improve their properties and performance.
\end{abstract}

\section{Introduction}

Titanium and its alloys are used in many different areas such as aerospace, automotive, sporting equipment, chemical, marine and medical due to their excellent high strength-to-weight ratio, good creep resistance, excellent corrosion resistance, good biocompatibility, etc [1, 2]. In general, titanium and its alloys can be divided into (i) unalloyed (also known as commercially pure - CP Ti), (ii) $\alpha$ and near $\alpha$ alloys, (iii) $\alpha+\beta$ alloys, and (iv) $\beta$ alloys. The characteristics including welding of these alloys are shown in Figure 1. Welding characteristics are crucial because a lot of titanium are available in sheets and plates forms. Depending on alloy classification, titanium and its alloys have moderate to excellent weldability [1]. Figure 1 indicates a better weldability of unalloyed or CP Ti, $\alpha$-alloys and near- $\alpha$ alloys compared with $\alpha / \beta$ alloys or $\beta$ alloys.

Titanium can be welded with arc welding i.e. high heat/energy input and low power density such as gas tungsten arc welding (GTAW), gas metal arc welding (GMAW), plasma arc welding (PAW), or with highenergy beam technique such as laser beam welding (LBW) and electron beam welding (EBW) [1, 2]. Depending on the method, the weld could result in a very narrow or fairly wide fusion zone (FZ) and heat affected zone (HAZ) due to the heat input experienced by the work piece.

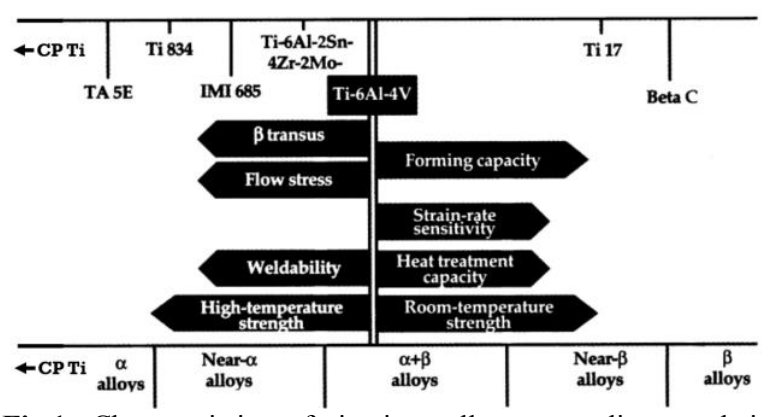

Fig.1. Characteristics of titanium alloys according to their group [1].

\subsection{Unalloyed titanium - Commercially Pure Titanium (CP Ti)}

The strengths of CP $\mathrm{Ti}$ are relatively lower than most other titanium alloys, but it has the best weldability. Typical yield strengths ranged from $170 \mathrm{MPa}$ to $480 \mathrm{Ma}$ [1]. Its strengths come from the strengthening elements i.e. oxygen and nitrogen in the form of $\alpha$ phase accompanied by some minor $\beta$ phase due to the presence of Fe [2]. Welding characteristics of CP Ti have been reported by various authors. Karpagaraj et al. [3] performed GTAW on CP Ti sheets with a thickness of 1.6 and $2 \mathrm{~mm}$ containing equiaxed alpha phase grains with the presence of fine and disperse precipitation of beta phase. They pointed out that the interface between

Corresponding author: tpasang@aut.ac.nz 
the BM and the HAZ where the thermal cycles occurred during the welding process. Due to this complex thermal cycle, the equiaxed grains had grown in larger size in the HAZ. Compared to the microstructure of the HAZ, there is an inhomogeneous growth of microstructure at the FZ. FZ of the weld bead obtained in GTAW is fairly wide and it is clearly differentiable. Based on the microstructural studies, the degree of grain coarsening decreases as one moves farther from the FZ to the BM. Gorinin et al. [4] reported a huge difference in microstructures between fast-cooled $\left(500^{\circ} / \mathrm{sec}\right)$ and slow-cooled $\left(20^{\circ} / \mathrm{sec}\right)$ of welded CP Ti samples. The fast-cooled sample had needle (martensite-like structure) and lamellar-shaped $\alpha$-phase, while the slow-cooled sample showed a coarse acicular $\alpha$. The HAZ consists of equiaxed transformed $\beta$ grains which increase in size as the FZ is approached. Within these grains, colonies of $\alpha$ phases are present. Cui $\mathrm{Li}$ at al. [5] also observed a significant grain coarsening occurred in the HAZ immediately adjacent to the base metal and the degree of grain coarsening increases as the grains move towards the centre of the fusion zone. They also pointed out that higher welding speeds $(5 \mathrm{~m} / \mathrm{min}$ vs. $4 \mathrm{~m} / \mathrm{min})$ resulted in fine-grained acicular alpha in the weld centreline because the higher welding speed leads to higher cooling rate. Lathabai et al. [6] reported columnar grains in the fusion zone (FZ) which were significantly coarser than those observed in the HAZ and base metal. The columnar grains in the fusion zone were a result of epitaxial growth from the HAZ. The HAZ consisted of equiaxed transformed $\beta$ grains which increase in size as the FZ is approached. Colonies of $\alpha$-phases were present within these grains. They also reported that hardness across the BM-HAZ-FZ was comparable. Note that all the tensile samples fractured at the weld area. Mitchell et al. [7] conducted electron beam welding on a $1.6 \mathrm{~mm}$ thick $\mathrm{CP} \mathrm{Ti}$ and found the hardness to be comparable between the weld zones (HAZ and FZ) and the BM (Figure 2). The base metal had a yield strength (YS) of $630 \mathrm{MPa}$, ultimate tensile strength (UTS) of $695 \mathrm{MPa}$ and elongation of around $27 \%$. Following welding the YS dropped to $530 \mathrm{MPa}$, UTS reduced to $660 \mathrm{MPa}$ and elongation to $22 \%$. The tensile tested samples fractured at the BM suggesting reliable weld joints. In brief, typically $\mathrm{CP}$ Ti welds have coarse columnar grains in the fusion zones (FZ) compared with the heat affected zones (HAZ) and the base metal (BM) [2-7]. In the HAZ, the degree of grain coarsening increases as one moves towards the centre of the FZ.

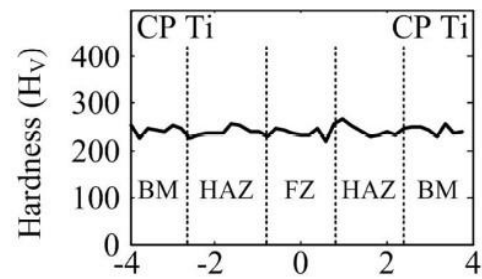

Fig. 2. Hardness profile of laser beam welded CP Ti [7].

\subsection{Near $\alpha$-alloy}

Chamanfar et al. [8] investigated properties and microstructure of a laser beam welded (LBW) near $\alpha$ titanium alloy sheet known as Ti-6Al-2Sn-4Zr-2Mo (Ti6242). The base metal (BM) had a bimodal microstructure with primary $\alpha$ and transformed $\beta$. The HAZ microstructure had a higher primary $\alpha$ volume fraction in the HAZ region near base metal while the FZ contained acicular $\alpha$-prime (martensite) (Figure 3 ). The $\mathrm{BM}$ had a yield strength (YS) of $880 \mathrm{MPa}$, ultimate tensile strength (UTS) of $1120 \mathrm{MPa}$ and elongation of $19.4 \%$. In the as-welded condition, the average YS was around $775 \mathrm{MPa}$, UTS was $977 \mathrm{MPa}$ and elongation of $13.4 \%$. So, there was a slight reduction in strength and ductility from the BM by about $12 \%, 13 \%$ and $31 \%$, respectively. Electron probe microanalysis (EPMA) demonstrated a uniform distribution of the main alloying elements across the weld. The hardness increased from the BM toward the HAZ and FZ (Figure 4) mainly due to a higher $\alpha$ volume fraction in HAZ and $\alpha$-prime formation in the FZ.
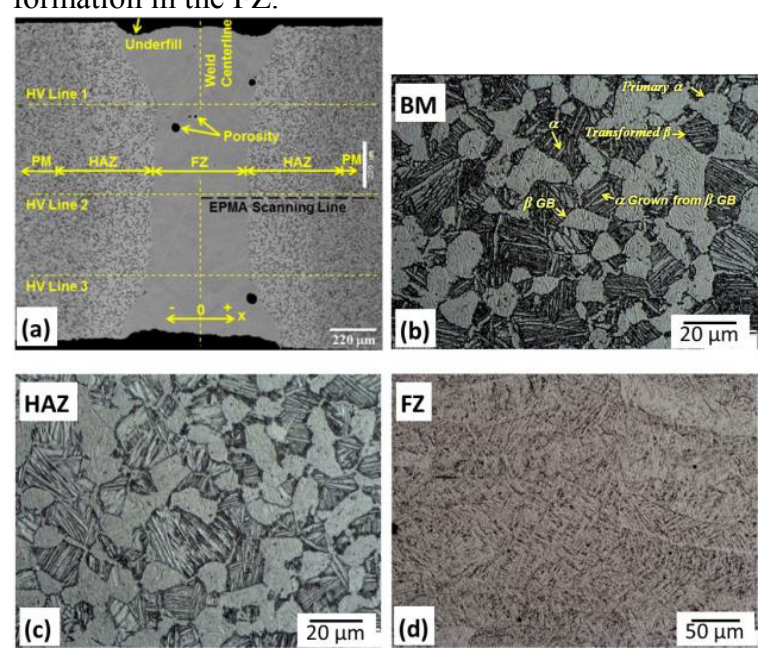

Fig. 3. (a) Weld profile of LBW Ti6242, (b) microstructure of BM showing bimodal structure of $\alpha$ and transformed $\beta$, (c) $\mathrm{HAZ}$ area showing larger grain size bimodal structure, and (d) $\alpha$-prime or martensite structure in the FZ area [8].

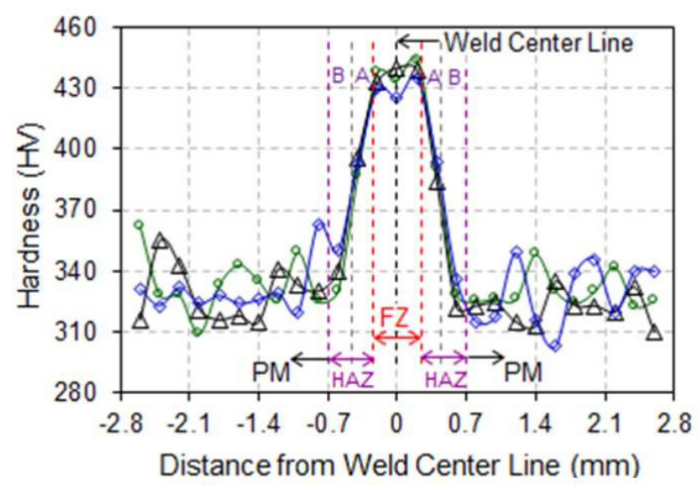

Fig. 4. Hardness profile of EBW Ti6242 showing an increased hardness in the HAZ and FZ due to the formation of $\alpha$ prime martensite [8]. 


\section{$1.3 \alpha+\beta$ alloy (Ti6Al4V)}

Ti6Al4V (Ti64) is, arguably, the most widely used titanium among all titanium alloys. It is commonly used as a reference against other titanium alloys. Ti64 has a great combination of properties such as strength and toughness as well as excellent corrosion resistance [1]. Upon fast cooling, this alloy is capable of producing martensite, hence, its strength provider. Weldability of Ti6Al4V (Ti64) has been investigated by various researchers. Akman et al. [9] investigated a laser welding of Ti64 and suggested a high cooling rates caused the formation of $\alpha$-prime in the FZ and HAZ region. While the FZ was predominantly occupied by $\alpha$-prime (martensite), the HAZ consisted of $\alpha$-prime (martensite) and acicular $\alpha$. The micro hardness profile across the weldment indicates that hardness in the FZ is higher than both the HAZ and BM. Mazumder and Steen [10] also conducted laser butt welding on Ti64 with $2 \mathrm{~kW}$ power. The BM had an annealed structure with dark $\beta$ in a bright $\alpha$ matrix. The HAZ had a mixture of $\alpha$-prime (martensite) and primary $\alpha$. The grains were larger in the near HAZ (near FZ) than in the far HAZ. The FZ consisted mainly of $\alpha$-prime within prior $\beta$-grain boundary. Sundaresan et al. [11] reported that rapid cooling and subsequent $\alpha$-prime transformation are effective strengthening methods for many titanium alloys. The observed large increase in hardness in laser welded Ti64 is due to high cooling rate associated with laser beam welding. The FZ of $\alpha / \beta$ alloys contains coarse, columnar prior beta grains. These grains may have originated from the near HAZ adjacent to the fusion boundary during solidification [11]. The grain structures of Ti64 welds showed the presence of a small amount of acicular $\alpha$, a larger amount of $\alpha$-prime in the HAZ and $\alpha$ prime covering the entire FZ [9,11]. Huiquang et al. [12] reported columnar grains in the FZ. They pointed out that the amount of lamellar structure increases (decreasing quantity of equiaxed grains) with heat input. Hardness profiles showed an increase in hardness due to the presence of $\alpha$-prime in the FZ compared with the BM. They suggested that the increase in hardness, hence less ductile, coupled with the presence of micropores contributed to the fracture in the weld region. The tensile tested samples fractured transgranularly with fine dimples on the fracture surface. Most recently, LBW of Ti64 were performed under conduction regime [18] and under keyhole regime [19], where both modes leading to butt welds with similar tensile properties than the unwelded base metal. In fact, these welded samples broke at the BM, confirming that the HAZ and FZ are stronger than the BM in the welded samples [18]. A study by Mitchell et al. [7] on welding of Ti64 by electron beam welding (EBW) suggested a slight increase in strength in the weld zone (HAZ and FZ). This is reflected in the increase of the tensile strengths where the unwelded base metal YS of $941 \mathrm{MPa}$, UTS of $983 \mathrm{MPa}$ and elongation of around 13\% compared to aswelded with YS around $960 \mathrm{MPa}$, UTS $1010 \mathrm{MPa}$ but a slight reduction in elongation to $8.5 \%$. In brief, the microstructure was principally $\alpha$-prime in the FZ and acicular $\alpha$ with $\alpha$-prime in the $\operatorname{HAZ}(1,9-12]$.

\subsection{Metastable $\beta$ and $\beta$ alloys}

An alloy is considered to be a $\beta$ alloy if it contains sufficient $\beta$ stabilizer alloying element to retain the $\beta$ phase without transformation to martensite on quenching to room temperature $[1,2,13]$. A metastable $\beta$ alloys have to have a minimum $M o_{e q}$ value of 10 (see formula below) to retain the $\beta$-phase at room temperature [13]. The higher the value of the $M o_{e q}$ of an alloy the higher the volume retention of the $\beta$ phase for the same cooling conditions. Metastable $\beta$ titanium alloys that can retain an apparently fully $\beta$-phase microstructure, are candidates for use in many demanding structural applications where light weight, impact toughness and high-strength are required $[1,2]$.

$M o_{e q}(w t . \%)=1.0 M o+0.67 \mathrm{~V}+0.44 \mathrm{~W}+0.28 \mathrm{Nb}+$ $0.22 \mathrm{Ta}+2.9 \mathrm{Fe}+1.6 \mathrm{Cr}-1.0 \mathrm{Al}$

Although relatively limited, investigations on weldability of $\beta$-titanium alloys have been conducted by various researchers. Becker and Baeslack [14] studied the properties and microstructure of welded Ti-15V-3Cr3Al-3Sn (Ti15-333), Ti8V-7Cr-3Al-4Sn-1Zr (Ti87341) and $\mathrm{Ti}-8 \mathrm{~V}-4 \mathrm{Cr}-2 \mathrm{Mo}-2 \mathrm{Fe}-3 \mathrm{Al}$ (Ti84223) and revealed lower strength in the weld zones (HAZ and FZ) compared with the BM. They also suggested that the alloys were weldable. Fracture modes of the weldments indicated transgranular microvoid coalescence. Liu et al. [15] studied the weldability of Beta-21S sheet using laser welding technique. They reported that the FZ and HAZ were narrow with fine retained $\beta$ grain structures. Epitaxial grain growth was observed in the narrow HAZ through the fusion boundary into the FZ. The FZ had transitioned from a solidification mode of a cellular-type along the fusion boundary to a completely cellulardendritic (or columnar dendritic) solidification mode at the weld centreline. Baeslack et al. [16] conducted welding investigations on Beta- $\mathrm{C}^{\mathrm{TM}}$ implementing gas tungsten arc welding (GTAW or TIG) and observed epitaxial growth from the near-HAZ into the FZ, which solidified with a cellular mode and progressively formed a complete columnar-dendritic grain structure at the weld centreline. The rapid cooling coupled with highbeta stability-containing elements ensure the retained $\beta$ phase in the weld region. The presence of retained $\beta$ phase is supported by the phase diagram (see Figure 9), wherein the $\beta$ alloys (Ti5553, Ti-10-23, and Ti-13-113 ) sit just beyond the martensite start where its formation is suppressed. A portion of the HAZ was heated above the $\beta$ transus during welding causing $\alpha$ precipitates to go back into solution. $\beta$-phase was fully retained upon fast cooling from above the $\beta$ transus, leaving an $\alpha$-free portion of the HAZ. The remainder of the HAZ was heated high enough in the $\alpha+\beta$ phase field to cause a reduction in volume fraction of the precipitated $\alpha$-phase at the transition from the BM to the HAZ. Consequently, there are two distinct regions in the HAZ, one which has exceeded the $\beta$ transus during welding (resulting in large grains) and another which has not.

Recently, a metastable $\beta$ titanium alloy known as Ti$5 \mathrm{Al}-5 \mathrm{~V}-5 \mathrm{Mo}-3 \mathrm{Cr}$ (Ti5553) has gained significant 
interest. Apart from its high strength, excellent hardenability and fracture toughness, this alloy also offers high fatigue resistance making it an ideal material for aircraft landing gear application [1,2]. A few other niche applications in the aerospace area have, since, been specified. For these applications, there may be a need to join them, e.g. by welding, and therefore its weldability needs to be investigated. Mitchell et al. [7] was the first to initiate welding investigation of Ti5553 by using electron beam welding (EBW). The hardness profile is shown in Figure 5 where lower hardness occurred in the HAZ and FZ. This is the opposite of hardness profile reported for $\alpha+\beta$ titanium such as Ti64. From tensile tests, it was revealed that all fractures took place in the FZ. This work was continued by Sabol et al [17], and is reported in the following section.

The tensile properties, strain distribution, fracture mechanisms, and microstructure of electron beam welded (EBW) Ti-5Al-5V-5Mo-3Cr (Ti5553) in the aswelded condition were investigated by Sabol et al. [17] in order to evaluate the weldability of this alloy [17]. Rolled sheets of Ti5553 were electron beam welded (EBW) perpendicular to the rolling direction and subsize tensile specimens were machined from the sheets. Microstructural examination showed the FZ and HAZ consisted of large grains of retained $\beta$ phase whereas the $\mathrm{BM}$ consisted of $\alpha$ surrounding small $\beta$ grains containing dispersed $\alpha$ precipitates (Figure 6).

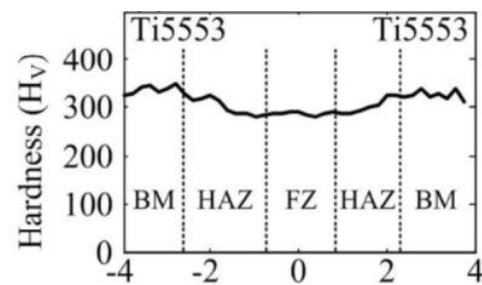

Fig. 5. Hardness profile of as-welded Ti5553 using laser beam welding [7].

Tensile tests revealed that elongation at fracture in the as-welded condition was comparable to un-welded Ti5553 while also revealing that the tensile strength was lower. Hardness profiles across the welds showed a decrease in average hardness from the base metals to the fusion zone (Figure 7). The decrease in hardness can be attributed to the large grain size, retained $\beta$ phase, and loss of Al during welding. Fracture occurred in the weld zone and was primarily due to microvoid coalescence (Figure 8). These results indicate that Ti5553 is readily weldable and displays reasonable properties in the aswelded condition.

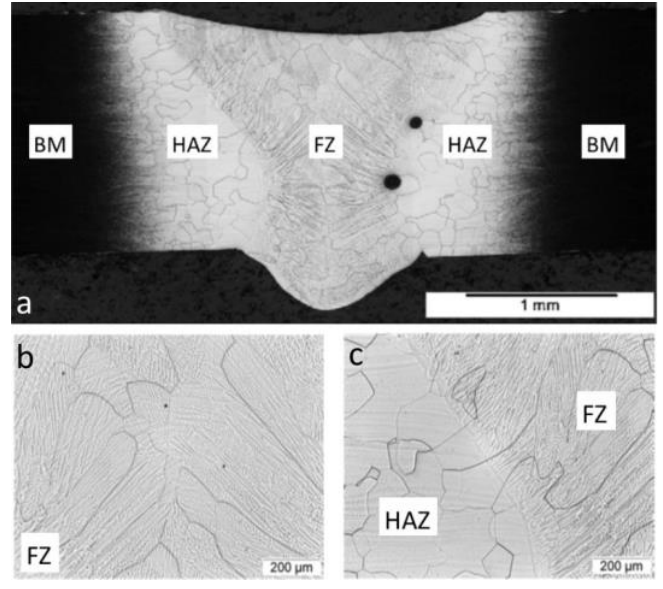

Fig. 6. (a) Weld profile of Ti5553 after EBW, and (b-c) micrographs showing grain structures in the HAZ and FZ [17].

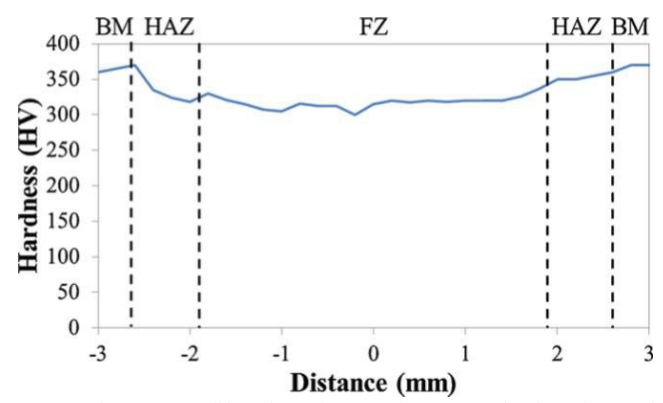

Fig. 7. Hardness profile showing a decrease in hardness in the HAZ and FZ area [17].

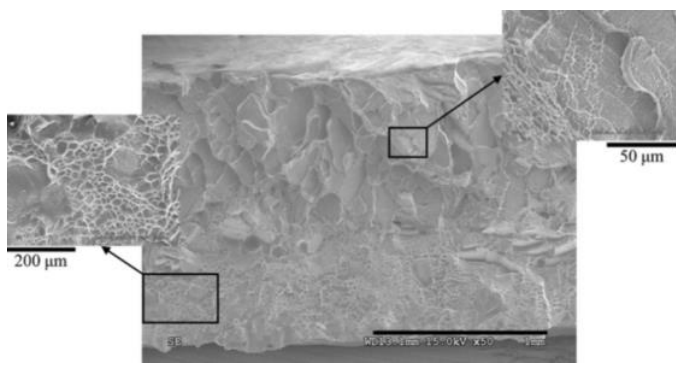

Fig. 8. SEM images showing dimples features on the fracture surface [17].

\section{Current investigations}

Apart from a brief summary on previous works, this paper also present the more recent results from an ongoing research on welding of titanium alloys at Auckland University of Technology. Figure 9 illustrates a simplified phase diagram showing locations of some common titanium alloys with respect to the titanium classification described in the introduction including those used in this investigation. In this article we reported the on-going welding results using gas tungsten arc welding (GTAW) or commonly known as tungsten inert gas (TIG) welding on a few different titanium across the phase diagram. The materials were $\mathrm{CP} \mathrm{Ti}$, Ti6al4V (Ti64) and Ti-5Al-5V-5Mo-3Cr (Ti5553) which represent the unalloyed (CP Ti), $\alpha+\beta$ alloys and $\beta$ alloy, respectively. Their chemical composition are presented 
in Table 1, and the microstructure prior to welding are given in Figure 10. The $\mathrm{CP}$ Ti had nearly equiaxed $\alpha$ grains with an average size of $20 \mu \mathrm{m}$ in the longitudinal direction. It also contained disperse $\beta$ phase (dark). The presence of $\beta$ phase is associated with the addition of small amounts of Fe in CP Ti. The Ti64 alloy had elongated primary $\alpha$ grains in the $\alpha / \beta$ matrix, while Ti5553 alloy showed typical $\alpha / \beta$ microstructure with globular $\alpha$ particles distributed within the $\beta$ matrix. These $\alpha$ particles have an average size of less than $5 \mu \mathrm{m}$. Figure 11 illustrates the sampling from a welded material.

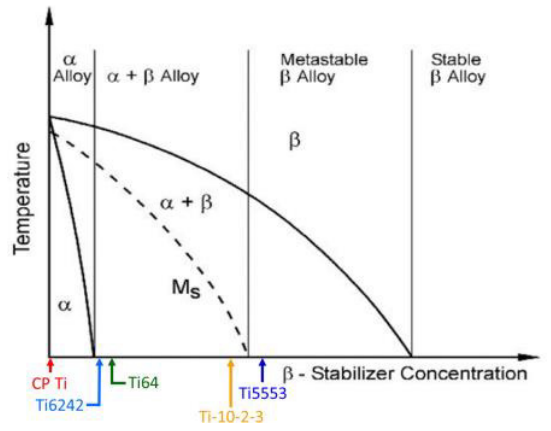

Fig. 9. A simplified phase diagram showing locations of various titanium alloys (modified from [1]).

Table 1: Chemical composition (wt.\%) of the three alloys used in this investigation

\begin{tabular}{|l|l|l|l|l|l|l|l|l|}
\hline & $\mathrm{Ti}$ & $\mathrm{Al}$ & $\mathrm{V}$ & $\mathrm{Mo}$ & $\mathrm{Cr}$ & $\mathrm{Fe}$ & $\mathrm{O}$ & $\mathrm{N}$ \\
\hline $\mathrm{CP} \mathrm{Ti}$ & Bal & 0.16 & 0.01 & 0.01 & 0.01 & 0.22 & 0.28 & 0.01 \\
\hline Ti64 & Bal & 6.08 & 3.85 & 0.01 & 0.02 & 0.17 & 0.05 & 0.01 \\
\hline Ti5553 & Bal & 5.03 & 5.10 & 5.06 & 2.64 & 0.38 & 0.14 & 0.01 \\
\hline
\end{tabular}

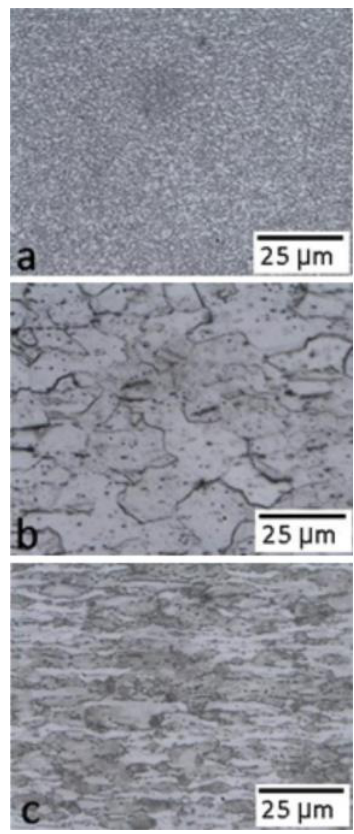

Fig. 10. Microstructure of (a) CP Ti, (b) Ti64 and (c) Ti5553.

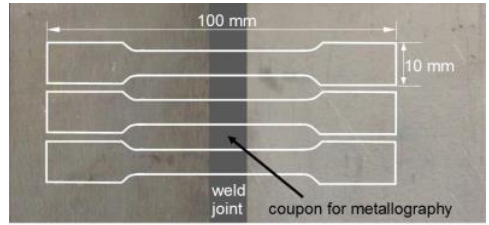

Fig. 11. Schematic diagram showing location for of the tensile and metallography samples, i.e. weld profiles and hardness

\subsection{Unalloyed titanium - Commercially Pure Titanium (CP Ti)}

The weld profile of the $\mathrm{CP}$ Ti-CP Ti butt joint using GTAW is given in Figure 12. The width of the FZ is around $8 \mathrm{~mm}$. This is much wider than those of EBW or LBW, i.e. around $2 \mathrm{~mm}$. The higher magnification micrographs showed BM material with equiaxed $\alpha$ grains - a typical structure in the annealed condition. The HAZ also had equiaxed grains with acicular $\alpha$ phase starting as smaller grains near BM and gets larger as it moves towards FZ area (Figures 12 and 13). The grains in the FZ area can be as big as $200 \mu \mathrm{m}$ consisting predominantly of acicular $\alpha$ phase (Figure 13). The hardness values were was consistent throughout the BMHAZ-FZ-HAZ-BM, i.e. between 250 to $270 \mathrm{HV}$ (Figure 14a). From tensile testing, it is clear that fracture took place at the BM (Figure 14b). The UTS was around 690 $\mathrm{MPa}$ and $560 \mathrm{MPa}$ for the $\mathrm{BM}$ and as-welded respectively. The fracture surface showed the presence of dimples indicating ductile fracture mechanism (Figure 15).

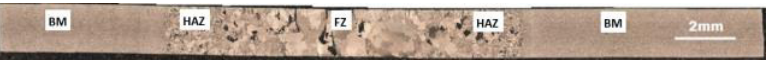

Fig. 12. Weld profile of CP Ti-CP Ti from GTAW from BMHAZ-FZ-HAZ-BM.

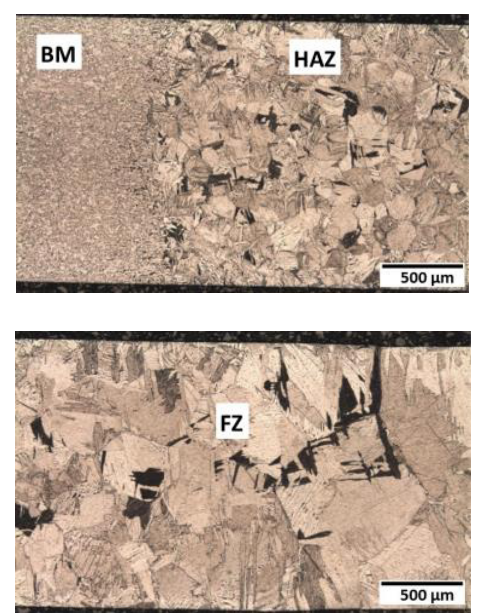

Fig. 13. Micrographs showing equiaxed grains in the BM and acicular $\alpha$ in both HAZ and FZ, but larger grains in the FZ. 

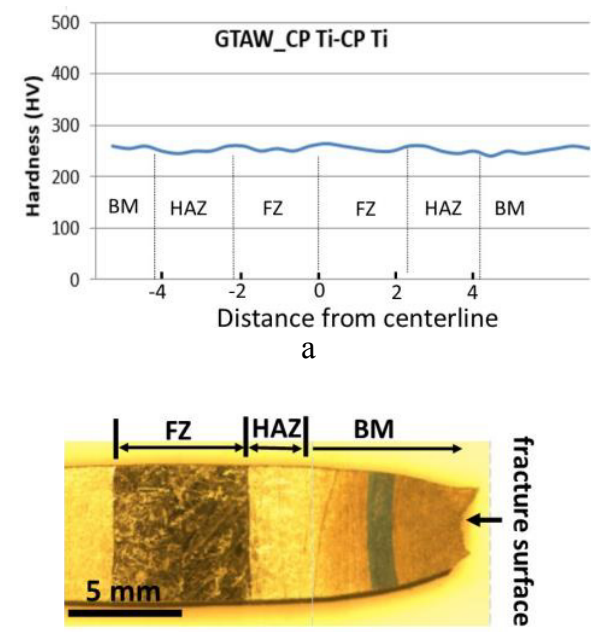

b

Fig. 14. (a) Hardness profile showing comparable hardness from BM-HAZ-FZ-HAZ-BM, and (b) fracture location of the tensile tested CP Ti-CP Ti showing fracture location at the BM.
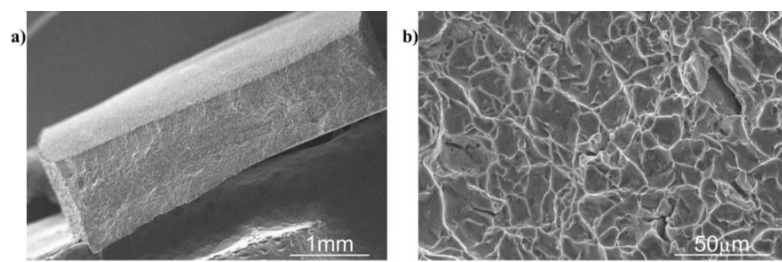

Fig. 15. SEM images showing (a) fracture location of $\mathrm{CP} T \mathrm{Ti}$ welds in the $\mathrm{BM}$, and (b) dimples features on the fracture surface.

\section{$2.2 \alpha+\beta$ alloy (Ti6Al4V or Ti64)}

The weld profile of the Ti64-Ti64 butt joint using GTAW is given in Figure 16. The width of the FZ is around $8 \mathrm{~mm}$. The higher magnification micrographs showed BM material with fine $\alpha$ grains aligned in the longitudinal direction indicating the material was, most likely, in the as-rolled condition. The HAZ had equiaxed grains with acicular $\alpha$ phase and some evidence of the presence of $\alpha$-prime (martensite). The grains were smaller near BM and gets larger as it moves towards FZ area (Figures 16 and 17). The grains in the FZ area were large, and predominantly populated by $\alpha$-prime and acicular $\alpha$ to a minor extent (Figure 17). The hardness profile showed an increase in the HAZ and FZ, i.e. from around $330 \mathrm{HV}$ in the $\mathrm{BM}$ to around $380 \mathrm{HV}$ in the FZ (Figure 18a). From tensile testing, it is clear that fracture took place at the fusion line, i.e. border between HAZ and FZ (Figure 18b). The UTS was around $980 \mathrm{MPa}$ and $890 \mathrm{MPa}$ for the $\mathrm{BM}$ and as-welded respectively. Dimples were also observed on the fracture surface (Figure 19) but much smaller and shallower compared to those observed in the CP Ti fracture surface.

\section{вM Anar}

Fig. 16. Weld profile of Ti64-Ti64 from GTAW.
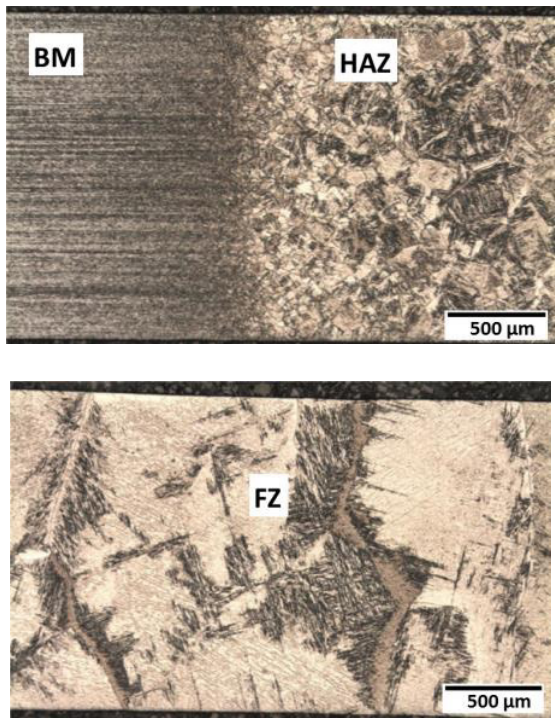

Fig. 17. Micrographs showing very fine grains in the BM, acicular $\alpha$ in the HAZ and mainly $\alpha$-prime in the FZ. Grains in the FZ were also larger.

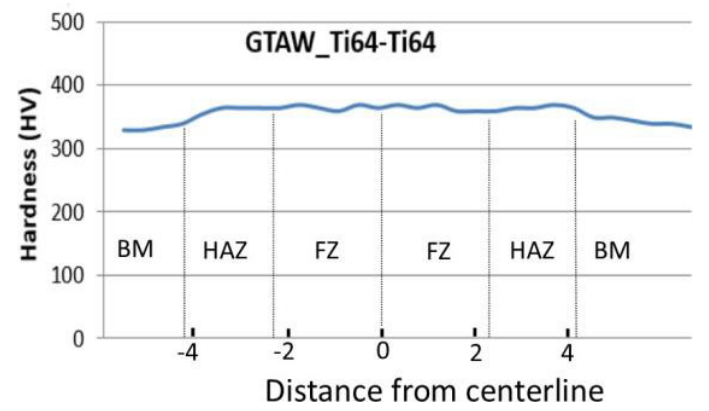

a

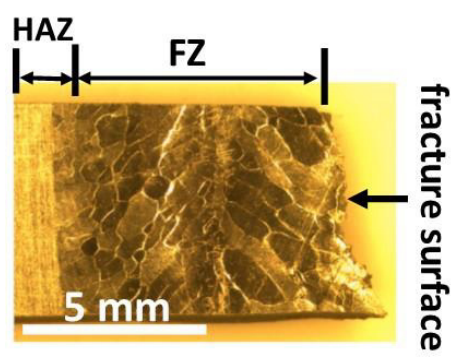

$b$

Fig.18. (a) Hardness profile of Ti64-Ti64 GTAW, and (b) fracture location of the tensile tested Ti64-Ti64 GTAW. 

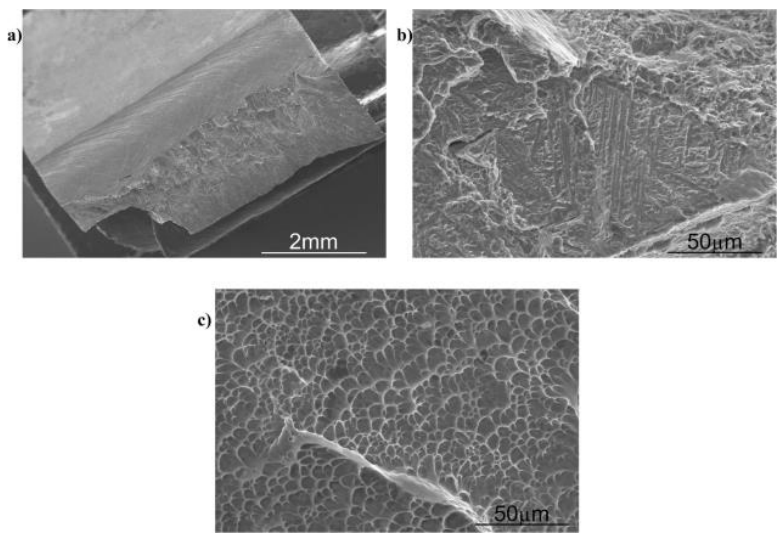

Fig. 19. SEM images showing fracture surface of a tensile tested Ti64-Ti64 butt weld.

\section{$2.3 \beta$ alloy (Ti-5Al-5V-5Mo-3Cr or Ti5553)}

The weld profile of the Ti5553-Ti5553 butt joint using GTAW is given in Figure 20. The width of the FZ is around $7 \mathrm{~mm}$ on the top surface and $4 \mathrm{~mm}$ at the bottom surface. This $\mathrm{V}$ shape is due to the relatively thin sheet used in this experiment, i.e. around $1.6 \mathrm{~mm}$ compared with around $2 \mathrm{~mm}$ and $2.4 \mathrm{~mm}$ thick for $\mathrm{CP} \mathrm{Ti}$ and Ti64, respectively. Although not very clear in the image, but the BM had a very fine grains resulting from forging. The HAZ is decorated with retained, equiaxed $\beta$ grains with larger grains at the fusion boundary and smaller grains towards BM. Epitaxial grain growth from the HAZs into the FZ was clearly observed (Figure 21). The FZ consisted of a columnar dendritic-typed grain morphology indicating a high concentration of $\beta$ stabilizing elements. The hardness profile showed a decrease in the HAZ and FZ, i.e. from around $380 \mathrm{HV}$ in the BM to around $300 \mathrm{HV}$ in the FZ (Figure 22a). From tensile testing, it appears that fracture occurred in the FZ (Figure 22b). The UTS was around $1050 \mathrm{MPa}$ and 720 $\mathrm{MPa}$ for the BM and as-welded respectively. This is consistent with the result from hardness which indicating low hardness in the FZ. Low magnification SEM image showed a brittle-type fracture, but at higher magnification, it is obvious that dimples were present on the fracture surface (Figure 23).

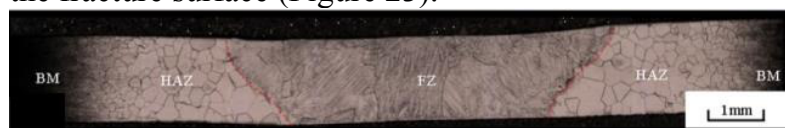

Fig. 20. Weld profile of Ti5553-Ti5553 from GTAW.

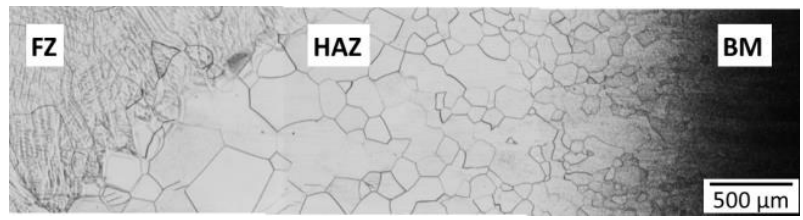

Fig. 21. Micrographs showing very fine grains in the BM (most likely as-forged), equiaxed grains with retained $\beta \alpha$ in the HAZ and columnar dendritic grains in the FZ.
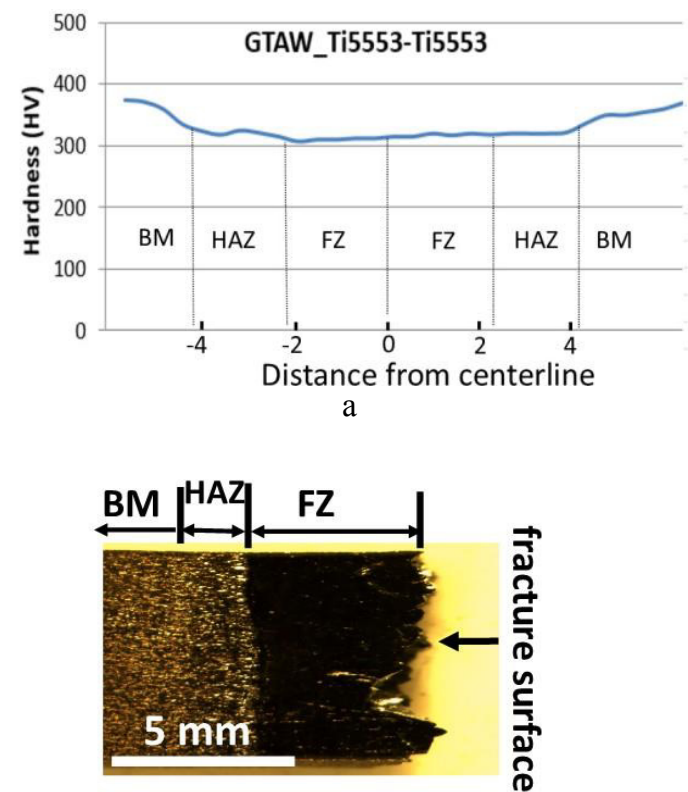

$\mathrm{b}$

Fig. 22. (a) Hardness profile of Ti5553-Ti5553 GTAW, and (b) fracture location of the tensile tested Ti5553-Ti5553 GTAW.

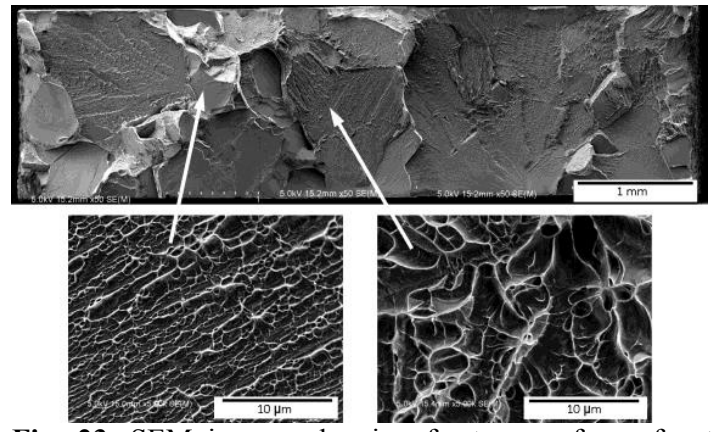

Fig. 23. SEM images showing fracture surface of a tensile tested Ti5553-Ti5553 butt weld.

\section{Summary}

A schematic diagram showing hardness profiles of aswelded titanium alloys is given in Figure 24 below. Although it is not comprehensive, it indicates the strength and weakness of certain areas across the welds. For unalloyed titanium, hardness remained constant throughout. Near $\alpha$ alloys and $\alpha+\beta$ alloys showed an increase of hardness in the HAZ and FZ, while the $\beta$ alloys showed a decrease of hardness, hence, low strength in the HAZ and FZ area. This implies a careful consideration when welding titanium alloys for an intended applications. It also suggested a proper post welding heat treatment (PWHT) is required to minimise the effect of strengthening or softening in the HAZ and FZ to avoid premature failures. 


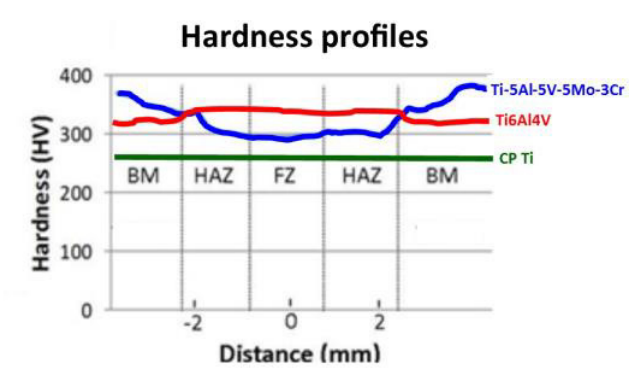

Fig. 24. General hardness profiles of various titanium alloys.

The author (TP) would like to thank the Loewy Foundation for providing support for the Institute for Metal Forming, Lehigh University where some of these research have been carried out. TP would also like to thank the Japan Society for the Promotion of Science (JSPS), and the Joining and Welding Research Institute (JWRI), Osaka University for the funding through JSPS Fellow to conduct laser welding at JWRI.

\section{References}

1. M.J. Donachie Titanium: A Technical Guide second Edition, ASM International (2004)

2. G. Lütjering, J.C. Williams, Titanium. Second edition, Berlin Springer (2003)

3. A. Karpagaraj, N. Sivashanmugam, Materials Science \& Engineering, A640, 180-189 (2015)

4. I.V. Gorinin, J.B. Florinsky, B.B. Chechukin, The Science, Technology and Application of Titanium, Pergamon Press, 843-848 (1968)

5. L. Cui, M. Kutusna, T. Simizu, K. Horio, F, Materials and Design, 30, 109-114 (2009)

6. S. Lathabai, B.L. Jarvis, K.J. Barton, Materials Science and Eng., A299, 81-93 (2001)

7. R. Mitchell, A. Short, T. Pasang, G. Littlefair, Structural Integrity and Failure - SIF, University of Auckland (2010)

8. A. Chamanfar, T. Pasang, A. Ventura, W.Z. Misiolek, Materials Science \& Engineering, A663, 213-224 (2016) 9. E. Akman, A. Demir, T. Canel, T. Sinmazcelik, Journal of Material Processing Tech., 209, 3705-3713 (2009)

10. J. Mazumder and W. M. Steen, Metallurgical Transactions A, 13a, 865 (1982)

11. S. Sundaresan, G.D. Janaki Ram, G. Madhusudhan, Mater Sci Eng A, 262:88-100 (1999)

12. W. Huiqiang, F. Jicai, H. Jingshan, Bulletin of Materials Science, 27, 387-392 (2001)

13. P.J. Bania (1993), Beta titanium alloys in the 1990's, TMS, Warrendale, PA, 3-14 (1993)

14. D. Becker, W.A. Baeslack III, Welding Journal, 59, 85-93 (1980)

15. P. Liu, K.H. Hou, W.A. Baeslack III, J. Hurley, Titanium '92, 1477 (1993)

16. W.A. Baeslack III, P.S. Liu, D.P. Barbis, J.R. Schley J.R. Wood, Titanium '92, 1469-1476 (1993)

17. J.C. Sabol, T. Pasang, W.Z. Misiolek, J.C. Williams, Journal of Materials Processing Technology, 212, 23802385 (2012)

18. J.M. Sánchez-Amaya, M. R. Amaya-Vázquez, F.J. Botana, Laser welding of light metal alloys: aluminium and titanium alloys (Ed. S. Katayama), AMAZON (UK), 215-254, 2013

19. X-L. Gao, L-J. Zhang, J. Liu, J-X Zhang. A comparative study of pulsed $\mathrm{Nd}$ :YAG laser welding and TIG welding of thin Ti6Al4V titanium alloy plate. Materials Science and Engineering: A, 559, 14-21, 2013 